\title{
A Case Report of Osteomyelitis of Lower End of Tibia and Fibula as a Complication of Elastic Rubber Band Syndrome (Dhaga Syndrome)
}

\author{
Anand Reddy Baddula ${ }^{1}$, Ranjith Kumar Yalamanchili ${ }^{1}$, Venu Madhav Vuthpala ${ }^{1}$ \\ Learning Point of the Article: \\ Any child mimicking acquired constriction band should be evaluated for elastic band sydrome
}

\section{Abstract}

Introduction: Rubber band syndrome is a rare acquired condition poorly discussed in literature, when neglected can lead to devastating complications of compartment syndrome and infection of soft tissue and bone as seen in the present case. Rubber band or Dhaga (sacred thread) when worn for prolonged duration can bury into the skin and soft tissue.

Case Report: A 12-month-old girl developed osteomyelitis of tibia and fibula as sequelae of misdiagnosis and treatment for this syndrome. Assuming it to be a simple constriction band, incisions were given on medial and lateral aspect of the ankle, later she developed osteomyelitis of the tibia and fibula with in buried rubber band, which was removed and thorough curettage done and achieved good healing of the bones.

Conclusion: Rubber band syndrome in not an uncommon condition, but when neglected or misdiagnosed can lead to complications such as compartment syndrome and osteomyelitis of the bones in involved limb as seen in this case. In suspected cases, imaging with sonography and Xray of involved helps in diagnosis.

Keywords: Osteomyelitis, rubber band syndrome, Dhaga syndrome, compartment syndrome.

\section{Introduction}

Rubber band syndrome also known as Dhaga syndrome is a rare acquired condition simulating constriction band syndrome seen in pediatric age group, which is poorly discussed in literature $[1,2,3,4,5]$. Elastic rubber band or sacred threads over the wrist or ankle when neglected can embed in to the skin, soft tissues, and even bone as the child grows. This can further lead to syndrome of complications such as compartment syndrome $[1,2]$ chronic infections of soft tissue, and bone $[1,2$, $3,5]$. Either rubber band or Dhaga (sacred thread) when worn for prolonged duration [6] and neglected can burrow into the skin and soft tissues, resulting in compartment syndrome of the limb distal to the compression. There will be reepithelialization of the skin over the band after due prolonged duration of time, mimicking a skin crease or constriction band clinically [9]. So far, the cases reported were of upper limb around the wrist $[1,2$,
$3,4,5,6,7]$, and only one case was reported to be around ankle [10] which was of superficial compression with soft-tissue infection. In this article, we report a case of embedded elastic rubber band, which was buried deep into the tibia and fibula leading to osteomyelitis of both bones as sequelae of misdiagnosis and treatment suspecting to be a simple constriction band.

\section{Case Report}

A 12-month-old child presented with fever, soft-tissue constriction, and discharging sinuses around her left ankle. Two months earlier, she developed swelling of foot and ankle with constriction band evident by skin crease and pigmentation around ankle to a local hospital, where she was evaluated with Xrays of the involved limb, showing a thin radiopaque band deep to the skin inside soft tissue (Fig. 1a). She was treated

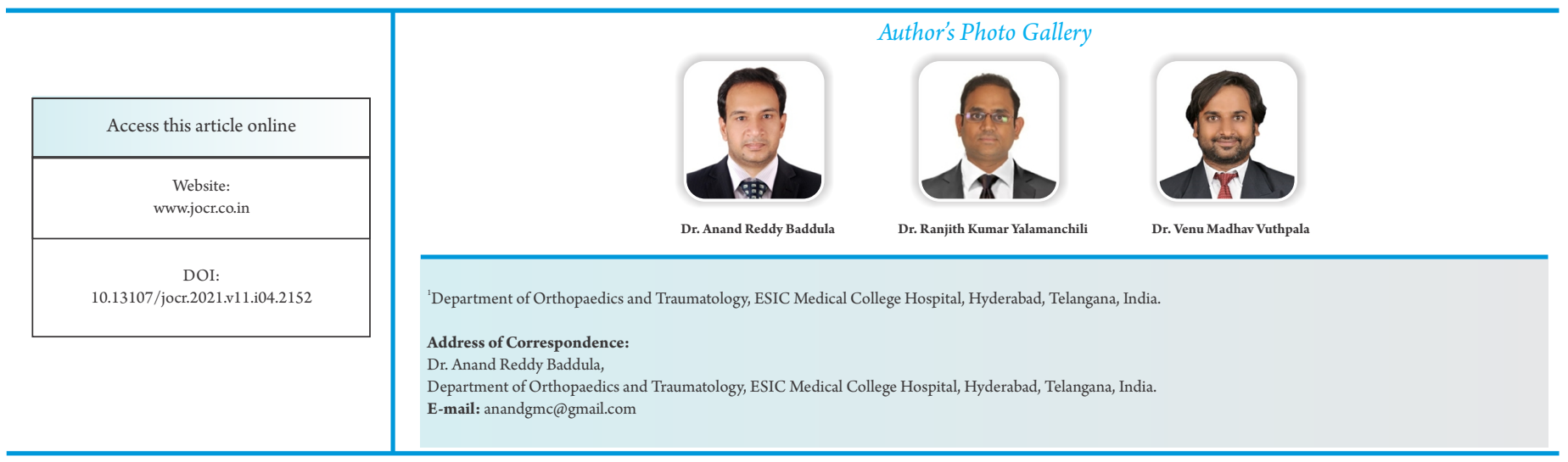

Journal of Orthopaedic Case Reports | pISSN 2250-0685 | eISSN 2321-3817 | Available on www.jocr.co.in | doi:10.13107/jocr.2021.v11.i04.2152 This is an Open Access article distributed under the terms of the Creative Commons Attribution Non-Commercial License (http://creativecommons.org/licenses/by-nc/3.0) which permits unrestricted non-commercial use, distribution, and reproduction in any medium, provided the original work is properly cited. 


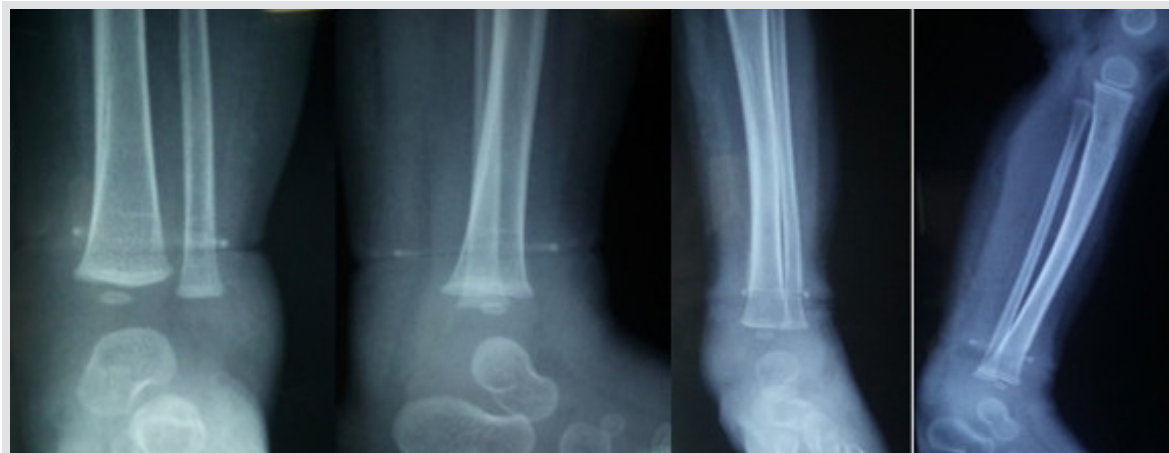

Figure 1: $(\mathrm{a}$ and $\mathrm{b})$ Two months and 1 month $\mathrm{X}$-rays before presentation showing a band deep to the soft tissue.

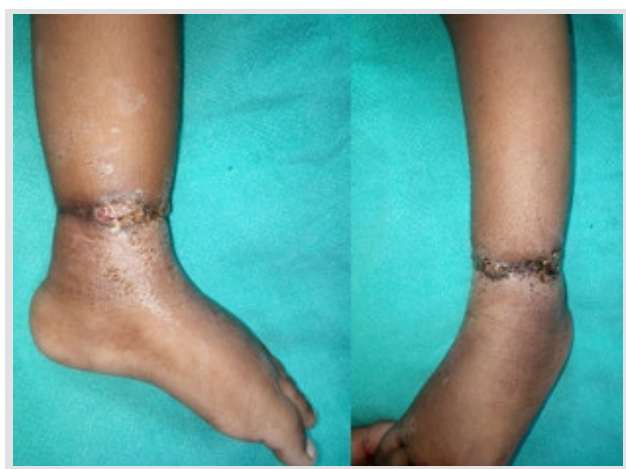

Figure 2: Clinical picture at the time of presentation with discharging sinuses. conservatively with analgesics and rest, only with mild improvement in the symptoms. She presented again after 3 weeks with exacerbation of the symptoms, and then, X-ray showed the radio-opacity deep to the soft-tissues adjacent to the both bones of leg (Fig. 1b) for which she was intervened with two linear skin incisions over medial and lateral aspect, aiming to break the constriction band. Post-surgery, the child did not show any signs of improvement and developed discharging sinuses over the incision sites, for which the patient was referred to us. On examination, the limb showed crusts and pigmented skin crease, (Fig. 2) with intact neurovascular status, X-rays showed deep constriction of soft tissue, thick periosteal reaction over the lower end of tibia and fibula, lytic lesion with buried radio-opaque foreign body inside the lesion (Fig. 3). High-resolution ultrasonography along with color Doppler revealed circular band deeply in the soft tissues excavating the bone with neurovascular bundle spared underneath (Fig. 4). Exploration with medial and lateral approaches over the skin lesions was done and an elastic rubber band identified encircling the tibia and fibula. The band was cut and pulled out, pus along with infective granulation tissue noted over the tibia and fibula was scooped (Fig. 5) and sent for culture sensitivity along with thorough curettage of the lesions (Fig. 6). Postoperatively, limb was immobilized and wound was regularly inspected. Cultures yielded Escherichia coli (heavy growth), antibiotics according to sensitivity were given for 6 weeks and wound healed well (Fig. 7) with no signs of infection as evident by disappearance of periosteal reaction in follow-up X-rays (Fig. 7).

\section{Discussion}

This case highlights the importance of rare but devastating complication of rubber band syndrome, which when left untreated or misdiagnosed can lead to osteomyelitis of the Figure 3: X-ray at the time of presentation involved bones. Elastic rubber showing lytic lesion with embedded rubber involved bones. Elastic rub ber band and thick periosteal reaction at the lower bands over the extremities may be end of tibia and fibula.

hidden underneath the sacred threads or anklets and are often not seen under the skin crease, especially in chubby babies and when these are neglected, result in prolonged compressive pressure of soft tissues that lead to swelling distally which again conceals the elastic band. As the baby grow, the band remains compressing the soft tissues and deeper structures. The consequale leads to cellulitis, compartment of limb distally, and osteomyelitis.

This syndrome was first described by Hogeboom in 1965 [10], since then only few cases were reported, most of them from Indian subcontinent as it is a part of the tradition to tie a sacred thread (Dhaga) around the limb in children, which when left for prolonged duration may cause the complications of compartment syndrome or osteomyelitis as in this case, leading to mutilated limb.

It is reinstated that parents should be discouraged from using such bands and threads around the limbs of the children and every case presenting with symptoms of compartment syndrome of the hand or foot should raise the suspicion and evaluated with X-rays and ultrasound to detect the constricting band. Early and timely intervention would save the limb form grave complications.

\section{Conclusion}

This case is reported due to its rarity and associated devastating complications. If left untreated or misdiagnosed, the child may land up with mutilated limb. Hence, it is necessary to emphasize

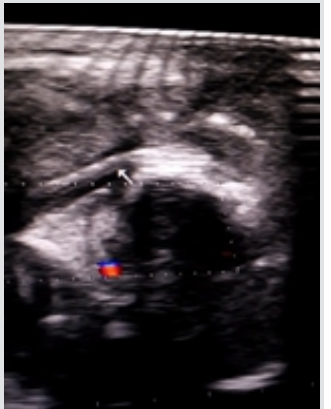

Figure 4: Vascular bundles deep to the band (arrow).

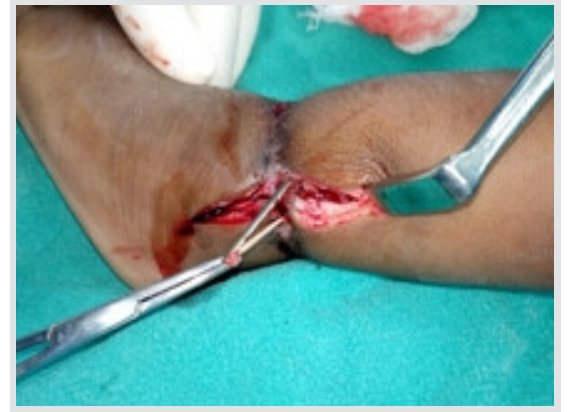

Figure 5: Intraoperative picture showing a rubber band deep inside the tissue. 


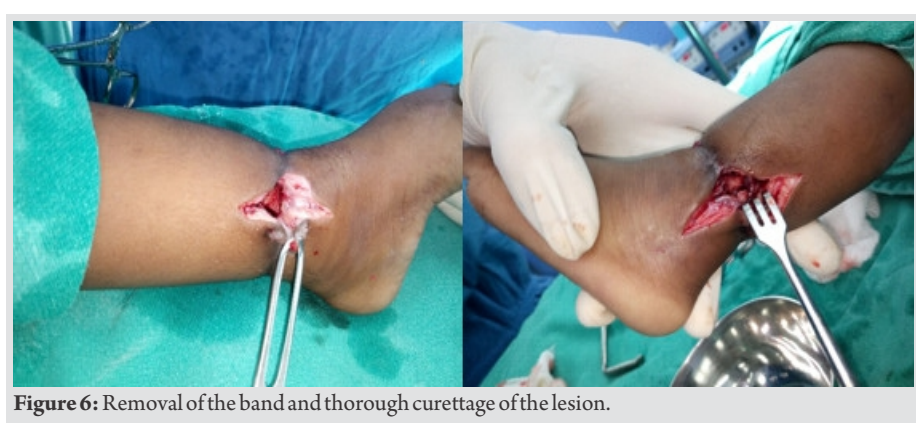

Figure 6: Removal of the band and thorough curettage of the lesion.

the occurrence of such rare diseases with sequelae do exist. It should be included in regular teaching curriculum for both undergraduate and postgraduates, particularly in Indian subcontinent.

\section{References}

1. Arora A, Agarwal A. Dhaga syndrome: A previously undescribed entity.J Bone Joint Surg Br 2004;86:282-4.

2. Agarwal A, Kant KS, Verma I. The rubber band syndrome: The forgotten rubber band in the wrist. Hand Surg 2013;18:407-10.

3. IOSRJournal of Dental and Medical Sciences 15:20-2.

4. McIver MA, Gochman RF. Elastic bands on the wrist : A not so "silly" complication. Pediatr Emerg Care 2011;27:428-9.

5. Gaur SC, Swarup A. Progressive constriction band caused by black magic thread.J Hand Surg Br 1991; 16:349.

6. Sreekanth R, Khanapur RI, Thomas BP. The elastic band (Dhaga) syndrome: Physicians and surgeons be aware. J

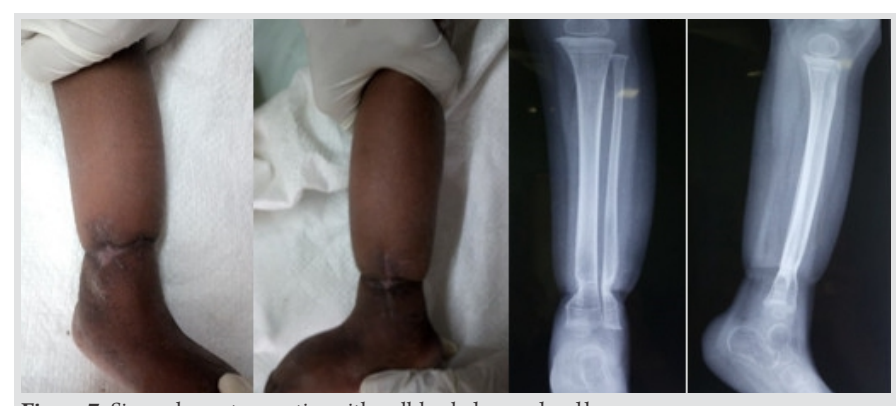

Figure 7: Six weeks post-operative with well-healed wound and bones.

Clinical Message

Diagnosing elastic band syndrome is quite challenging as there may not be proper history from parents, misdiagnosing can lead to devastating complications, imageology beginning with sonography and $\mathrm{X}$-ray helps in diagnosis.
Hand Surg Am 2014;39:810-1.

7. Rasool MN, Stathoulis B. Rubber band constriction of the wrist.J Hand Surg Br 1996;21:806-7.

8. Kumar KM, Shankarappa M. Rubber band syndrome of the arm.J Hand Microsurg 2013;5:83.

9. Kumar P, Kumar B, Singh K. A constriction ring of the thigh secondary to a rubber band. Plast Reconstr Surg 1995;95:209-10.

10. Yang G, Huang Y, Ye W, Yu H, Mei H. A rare case report of acquired rubber band syndrome due to an unnoticed rubber band on a baby's ankle. Transl Pediatr 2020;9:66-9.

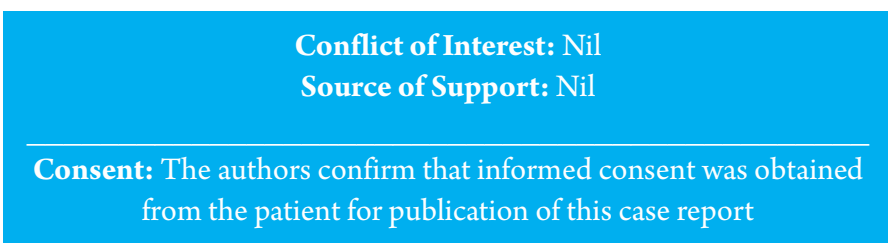

\section{How to Cite this Article}

Baddula AR, Yalamanchili RK, Vuthpala VM. A Case Report of Osteomyelitis of Lower End of Tibia and Fibula as a Complication of Elastic Rubber Band Syndrome (Dhaga Syndrome). Journal of Orthopaedic Case Reports 2021 April;11(4): 56-58. 